\title{
KAJIAN INTERIOR RUANG TIDUR PADA ANAK
}

\author{
Juli Atika \\ Program Studi Desain Interior Fakultas Seni dan Desain Universitas Potensi Utama \\ ranihermita@gmail.com
}

\begin{abstract}
ABSTRAK
Ruang tidur pada anak berpengaruh bagi kenyamanan anak agar anak lebih menyukai suasana ruang tidur, maka dari itu di bentuklah kajian interior ruang tidur pada anak, dengan adanya perubahan pada ruang tidur anak ini dapat mendapatkan ide bahwa untuk mendapatkan posisi yang nyaman untuk anak penulis membuat kajian interior ruang tidur pada anak bahwa dalam kajian tersebut penulis mendapatkan perbandingan dari kajian yang sebelumnya, dimana posisi untuk kenyamanan anak ini sangat diutamakan agar anak tersebut nyaman dengan ruang tidurnya masingmasing. Hasil survey lapangan dan berbagai ide dalam sebuah kajian ini yang dilakukan menunjukkan bahwa sebuah tempat tidur anak dapat dikembangkan lebih lanjut jika ditinjau dari nilai fungsi dan jangka waktu penggunaan yang terkadung dalam benda tersebut. Dengan menggunakan beberapa tahap metode yaitu pengumpulan data, pengelolaan data, tahap analisis data dan diakhiri dengan tahap perancangan, diharapkan dapat mencapai suatu rancangan baru yaitu sebuah interior ruang tidur untuk anak yang dapat memenuhi kebutuhan sesuai dengan aktivitas dan perkembangan anak yang mudah diaplikasikan dan dapat disesuaikan dengan keperluan.
\end{abstract}

Kata Kunci : Anak, interior, ruang tidur

\section{ABSTRACT}

The effect of color on a child's bedroom is very influential for the comfort of children so that children can be more comfortable and get a healthy life, therefore in the form of a study of the interaction of sleep in children, with changes in the child's space as researchers make feasibility in color and color it's not too flashy to make it look more comfortable. Childhood is very long in its life span, because at that time someone will also learn about life. The interior used in the children's room is based on the psychology that affects children at an early age, this effect in the interior shows that this study is very important to find out whether the child is comfortable with changes in their living space. optimal.

Keywords: Child, interior, bedroom, color

\section{PENDAHULUAN}

Anak - anak umunya memiliki sifat yang berbeda dengan orang dewasa, dimana anakanak lebih dominan serta sukar beradaptasi atau menyesuaikan diri dengan suasana dan lingkungan baru yang belum pernah mereka temui sebelumnya.Pertama kali anak beradaptasi dengan lingkungannya yaitu ketika anak mengenyam pendidikan di luar rumah. Seringkali terlupakan bahwa perkembangan seorang anak dapat dipengaruhi bukan hanya dari lingkungan psikis saja, namum juga dipengaruhi oleh lingkungan fisik. 
Lingkungan fisik sangat berpengaruh dan memiliki andil yang cukup besar di dalamnya. Serta bagaimana anak tersebut lebih nyaman dengan suasana interior yang ada didalam kamar pada anak.

Kamar tidur yang nyaman merupakan dambaan setiap orang. Untuk memperoleh kamar tidur yang nyaman dibutuhkan beberapa sentuhan elemen interior yang dapat menunjang dan meningkatkan rasa nyaman tersebut, salah satunya adalah dengan cara memilih warna cat dinding kamar tidur yang cocok bagi individu yang menempati kamar tidur tersebut. Menurut Cahaya Lituhayu, ruang yang ditempati seseorang memiliki pengaruh kuat terhadap kondisi psikologis orang tersebut. Menurut M. Sa hid Indraswara (2007), warna memiliki peran penting yang mendukung terciptanya suasana nyaman dan dapat mempengaruhi psikologis penghuni.

Menurut Cahaya Lituhayu, ruang yang ditempati seseorang memiliki pengaruh kuat terhadap kondisi psikologis orang tersebut. Pemilihan warna yang salah dan pemakaian warna yang tidak serasi dapat menyebabkan sebuah ruangan menjadi tidak nyaman (M. Sahid Indraswara, 2007).

Interior ruang tidur pada anak terdapat pada sisi tempat tidur serta ruang belajar pada anak, agar membuat anak nyaman dengan posisi lokasi kamar pada anak tersebut, sehingga dengan posisi interior yang sudah peneliti kaji dapat meningkatkan daya keinginan anak untuk lebih mencintai lingkungan rumah. Kamar tidur anak dari satu keluarga dengan keluarga lainnya pasti berbeda, ada yang masing-masing anak diberikan kamar tidur sendiri, ada pula yang tidur berbagi terlepas dari harus berbagi ruang atau memiliki ruang sendiri, desain kamar tidur anak akan sangat mempengaruhi betah atau tidaknya seorang anak di rumah. Nyaman bagi anak, luas dan indah, mudah dirapikan dan dibersihkan oleh orangtua, sesuai budget, adalah beberapa faktor yang dipertimbangkan ketika mendesain kamar anak.

\section{STUDI LITERATUR}

Dalam penulisan makalah ini, penulis banyak melakukan studi literatur pada bukubuku, tesis, jurnal dan penelitian berkaitan tentang kajian interior terhadap ruang tidur pada anak yang telah dilakukan oleh pengkarya sebelumnya. Data yang di dapat dari studi literatur ini digunakan sebagai acuan dalam membuat kajian terhadap interior bangunan. Tujuan dalam kajian interior ini terdapat beberapa ruangan yang akan dikaji dalam sebuah bangunan interior pada ruang tidur pada anak.

Terdapat beberapa elemen didalam ruangan tidurvpada anak termasuk salah satunya yaitu Interior posisi tempat tidur serta ruang belajar yang dibentuk melalui elemen-elemen pembentuk yang saling terkait. Elemen-elemen tersebut menjadi hal yang paling mendasar dalam perancangan interior suatu ruangan

Adapun elemen-elemen interior terdiri dari:

1. Plafond: bagian dari interior yang berada di paling atas sebagai penutup ruang.

2. Dinding: bagian sari interior yang posisinya di tengah/mengelilingi/membentuk ruang sebagai pembatas ruangagar anak-anak lebih nyaman dengan dinding tersebut dengan didesain dengan karikatur anak.

3. Lantai: bagian paling bawah dari ruangan sebagai alas ruang tersebut.

Menurut Francis D. K. Ching (Chng \& Binggeli, 2012) interior desain adalah Interior design is the planning, layout, and design of the interior spaces within buildings. These 
physical settings satisfy our basic need for shelter and protection,set the stage for and influence the shape of our activities, nurture our aspirations, express the ideas that accompany our actions, and affect our outlook, mood, and personality. The purpose of interior design, therefore, is the functional improvement, aesthetic enrichment, and psychological enhancement of the quality of life in interior spaces. Definisi di atas menjelaskan bahwa desain interior adalah sebuah perencanaan tata letak dan perancangan ruang dalam di dalam bangunan. Keadaan fisiknya memenuhi kebutuhan dasar kita akan naungan dan perlindungan, mempengaruhi bentuk aktivitas dan memenuhi aspirasi kita dan mengekspresikan gagasan yang menyertai tindakan kita,disamping itu sebuah desain interior juga mempengaruhi pandangan, suasana hati dan kepribadian kita. Oleh karena itu tujuan dari perancangan interior adalah pengembangan fungsi, pengayaan estetis dan peningkatan psikologi ruang interior. Secara garis besar elemen interior yang dikaji dapat dijelaskan secara sebagai berikut :

Elemen - Elemen Dasar Interior

1. Elemen Lantai Lantai merupakan salah satu elemen terpenting dalam sebuah interior. Lantai merupakan batas bawah bagi interior sebuah ruang. Lantai terbentang secara horisontal. Treatment yang dapat diterapkan pada lantai bermacam macam mulai dari penggunaan 2 berbagai material, pengaplikasiaan perbedaan ketinggian lantai, dan pengaplikasian esensi - esensi bentuk.

2. Elemen Dinding Dinding merupakan elemen interior yang membatasi interior ruang. Dinding terbentang secara vertikal dan merupakan bidang terbesar dalam interior ruang. Pengolahan dinding haruslah tepat karena dinding merupakan bidang dominan suatu interior ruang. Dinding dapat diaplikasikan dengan berbagai material finishing, material pembentuk, pencahayaan, dll.

3. Elemen Ceiling/ Langit - Langit Ceiling merupakan pembatas interior yang terbentang secara horisontal pada bagian teratas interior. Ceiling merupakan bagian interior yang pada umumnya tidak begitu diperhatikan oleh masyarakat awam, namun dengan diaplikasikannya beberapa desain tepat pada ceiling, dapat menimbulkan efek yang lebih baik. Treatment ceiling dapat berupa pengaplikasian berbagai material, perbedaan ketinggian, dan pengaplikasian bentuk bentuk pada ceiling.

4. Elemen Estetis Interior harus mengandung elemen estetis yang mengacu pada prinsip desain seperti proporsi, skala ruang, keseimbangan, harmoni ruang, kesatuan dan variasi ruang, irama ruang, penekanan ruang dan hal - hal keindahan seperti asesoris ruang.

5. Elemen Bukaan Bukaan pada elemen ruang adalah jendela, pintu, dan lubang sirkulasi. Dengan adanya bukaan, maka memungkinkan terjadinya pertukaran udara yang baik, sehingga ruangan menjadi nyaman dan sehat.

6. Elemen Cahaya Cahaya merupakan elemen interior yang tidak dapat dilupakan, tanpa adanya cahaya tidak akan ada kehidupan, dan manusia tidak dapat melihat. Interior ruang memerlukan pencahayaan yang cukup intensitasnya. Ambience ruang akan terbentuk dengan adanya pengaplikasian pencahayan dengan benar.

\section{PEMBAHASAN}

Anak sebagai calon generasi penerus bangsa, dalam membuat salah satu kreatifitas untuk anak para orang tua sangat memerlukan kenyamanan pada anak, terkhusus untuk ruang hunian agar anak lebih betah untuk berada di rumah salah satunya para orang tua lebih memperhatikan kawasan ruang hunia pada anak yaitu : 
1. Memenuhi Ttuntutan fungsi, sebagai ruang untuk tidur yang sehat dan nyaman, dalam hal ini termasuk ukuran dan lokasi tidur anak.

2. Memenuhi tuntutan estetika, yaitu memiliki tuntutan yang serasi, harmonis, selaras, dan sejalan dengan karakter penghuni.

Untuk memenuhi syarat yang ada di atas agar anak tersebut nyaman dan mendapatkan ruang huni kamar yang nyaman dapat dilakukan dan menatanya. dengan sebagai berikut : memiliki sirkulasi udara yang nyaman, terdapat pencahayaan pada kamar tidur anak, serta bahan interior yang dipakai oleh ruang kamar tidur anak tersebut.

Interior adalah, Menurut bahasa Inggris, interior mempunyai arti "Things that are on the inside of buildings" Jadi interior adalah bagian alam dari gedung/bangunan. Desain interior mempunyai tujuan menciptakan suasana ruang agar menjadi lebih baik, lebih indah, dan lebih anggun sehingga dapat memuaskan dan menyenangkan bagi para pemakai ruang. Tujuan tersebut dapat tercapai dengan menerapkan beberapa cara antara lain :

- Pemilihan dari material dan elemen ruang yang sesuai dengan fungsinya.

- Pengaturan keserasian dalam penyusunan perabot.

- Dimensi perabot yang proposional terhadap besaran ruang.

- Menciptakan suasana ruang yang sesuai dengan fungsi dan kehendak pemakai.

- Pengaturan perabot sesuai dengan tujuan dan fungsinya dengan tidak mengabaikan sirkulasi pemakai ruang.

- Pengaruh warna dan pola dekorasi ruang sangat penting dalam menciptakan kesan psikologis dan optis pada pemakai ruang tersebut.

Terdapat tujuh prinsip dasar yang diwadahi dalam interior design, antara lain :[3]

\section{Unity and Harmony}

Yaitu suatu ruangan dianggap sebagai suatu kesatuan dimana semua elemen yang ada saling melengkapi dan berkesinambungan satu dengan yang lainnya sehingga menghasislkan komposisi yang seimbang.

\section{Keseimbangan (Balance)}

Keseimbangan berarti tidak "berat" sebelah. Tidak terlalu condong ke sisi sebelah kanan atau kiri atau atas dan sebagainya. Segala sesuatu yang seimbang akan menciptakan unity dan harmony.

Keseimbangan dibagi menjadi 3 yaitu:

- Keseimbangan Simetris: Keseimbangan simetris terjadi apabila berat visual dari elemen-elemen desain terbagi secara merata baik dari segi horizontal maupun vertikal. Gaya ini mengandalkan keseimbangan berupa dua elemen yang mirip dari dua sisi yang berbeda.

- Keseimbangan Asimetris: Keseimbangan asimetris terjadi ketika berat visual dari elemen desain tidak merata di poros tengah halaman. Gaya ini mengandalkan permainan visual seperti skala, kontras, warna untuk mencapai keseimbangan dengan tidak beraturan.

- Keseimbangan Radial: Adalah ketika semua element desain tersusun dan berpusat di tengah. Misalnya: Tangga berbentuk spiral. 


\section{Vocal Point}

Vocal Point disini maksudnya adalah aksen yang menjadi daya tarik ruangan. Bisa satu atau lebih. Misalnya vocal point pada ruangan adalah jendela besar yang ada di ruangan, perapian atau bisa juga lukisan. Pemberian warna atau detail dan bentuk tertentu juga dapat dijadikan sebagai vocal point.

\section{Ritme}

Dalam desain interior, ritme adalah semua pola pengulangan tentang visual. Ritme didefinisikan sebagai kontinuitas atau pergerakan terorganisir.

\section{Detail}

Detail pada desain interior mencakup segala kelengkapan yang ada pada ruangan. Mulai dari furniture utama, furniture tambahan, hingga furniture artivasial. Detaildetail tersebut juga berpengaruh besar terhadap suasana ruang yang tercipta.

\section{Skala dan Proporsi}

Kedua prinsip desain yang berjalan beriringan, karena keduanya berhubungan dengan ukuran dan bentuk. Skala dan proporsi disini berpengaruh terhadap tingkat kenyamanan civitas yang berada di dalam ruangan.

\section{Warna}

Warna pada desain interior berpengaruh terhadap mood dan suasana ruang. Warnawarna yang soft akan cenderung menciptakan suasana ruang yang menenangkan, sedangkan warna-warna cerah akan memberikan suasana ruang yang menyegarkan.

Pengertian Interior Menurut bahasa Inggris, interior mempunyai arti "Things that are on the inside of buildings" Jadi interior adalah bagian dalam dari gedung/bangunan. Desain interior mempunyai tujuan menciptakan suasana ruang agar menjadi lebih baik, lebih indah, dan lebih anggun sehingga dapat memuaskan dan menyenangkan bagi para pemakai ruang.Tujuan tersebut dapat tercapai dengan menerapkan beberapa cara antara lain :

- Pemilihan dari material dan elemen ruang yang sesuai dengan fungsinya.

- Pengaturan keserasian dalam penyusunan perabot.

- Dimensi perabot yang proposional terhadap besaran ruang.

- Menciptakan suasana ruang yang sesuai dengan fungsi dan kehendak pemakai.

- Pengaturan perabot sesuai dengan tujuan dan fungsinya dengan tidak mengabaikan sirkulasi pemakai ruang.

- Pengaruh warna dan pola dekorasi ruang sangat penting dalam menciptakan kesan psikologis dan optis pada pemakai ruang tersebut.

\section{Elemen Interior}


Interior suatu ruangan mempunyai elemen-elemen pembentuk, elemen-elemen tersebut saling terkait dan hal yang paling mendasar dalam perancangan interior suatu ruangan.

\section{Elemen-elemen interior terdiri dari :}

- Plafond: bagian dari suatu interior yang posisinya berada paling atas.

- Dinding: bagian dari suatu interior yang posisinya berada di tengah dan mengelilingi atau membentuk ruan tersebut.

- Lantai: merupakan bagian paling bawah dari ruangan yang mengalasi ruang tersebut.

- Furniture: adalah perabot yang mengisi suatu interior, pemilihan dan penataan furniture

\section{Pembentukan Ruang Tidur Anak}

\section{Lantai}

Lantai pada ruang tidur anak ini memiliki warna yang menarik yang berfungsi sebagai penyemangat anak untuk lebih mencintai ruang tidur mereka masing-masing sehingga dengan adanya penbuatan kamar anak ini sangat bermanfaat bagi seluruh masyarakat yang ingin membuat ruang tidur untuk anak mereka masing-masing. Selain itu terdapat beberapa furniture yang berada di kamar anak seperti lemari belajar dan tempat tidur anak serta baground untuk memperindah tampilan pada area kamar anak tersebut.

\section{Dinding}

Dinding yang ada didalam kamar anak memiliki baground yang lucu seperti gambar kartun dan gambar yang berbau khas anak-anak, dimana dalam baground yang menampilkan gambar anak ini sangat berarti untuk tingkat kesenangan anak-anak, serta dapat memperindah tampilan pada ruangan tersebut. Baground yang terdapat pada kamar ini memiliki warna yang elegan serta tidak mencolok karena warna yang elegan bisa memperindah tampilan dari sinar matahari serta pencahayaan pada ruang tidur.

\section{Plafon}

Model plafon kamar tidur anak yang digunakan yaitu plafon minimalis dengan motif yang unik. Terdapat banyak sekali model plafon kamar tidur anak dengan motif unik yang bisa kita temukan dengan mudah mulai dari motif kartun hingga motif lainnya yang tentunya sebelum kita menentukan motifnya kita terlebih dahulu harus menentukan gayanya terlebih dahulu. Biasanya model plafon kamar tidur anak yang sering digunakan yaitu model plafon dengan gaya minimalis yang mana dengan motif minimalis ini tentunya akan sangat mudah untuk dibentuk dan juga didesain yang dipadukan dengan motif-motif yang unik sesuai dengan selera kita masing-masing serta dengan keinginan dari anak. 
Furniture yang terdapat pada ruang tidur anak ini sangat banyak ada terdapat tempat tidur, meja belajar, lemari pakaian serta lampu duduk untuk di meja belajar, dengan adanya furnitur ini tampilan pada kamar tidur semakin kelihatan indah serta menarik. Serta dalam furniture ini kita dapat menata ruangan dengan serapi mungkin.

5. Elemen pelengkap : elemen pelengkap suatu interior, misalnya: pintu, jendela, tangga sehingga pada ruang tidur tersebut memiliki kesan yang menari untuk

\section{Bentuk Ruang}

Bentuk Dan Elemen Ruangan tidur anak bentuk ruang yang dibatasi oleh dinding, lantai dan plafond memberi rasa terlindung, orang yang mendiami atau memandang sebuah ruang akan menilainya menurut seleranya sendiri. Interpretasi yang muncul bisa timbul kesan luas, tetapi juga bisa timbul kesan sempit. Bentuk ruang akan mempengaruhi psikis dari pemakai ruangan, hal ini dapat dengan memakai bentuk-bentuk dinamis agar menarik, disamping itu disesuaikan karakter kegiatan didalamnya.

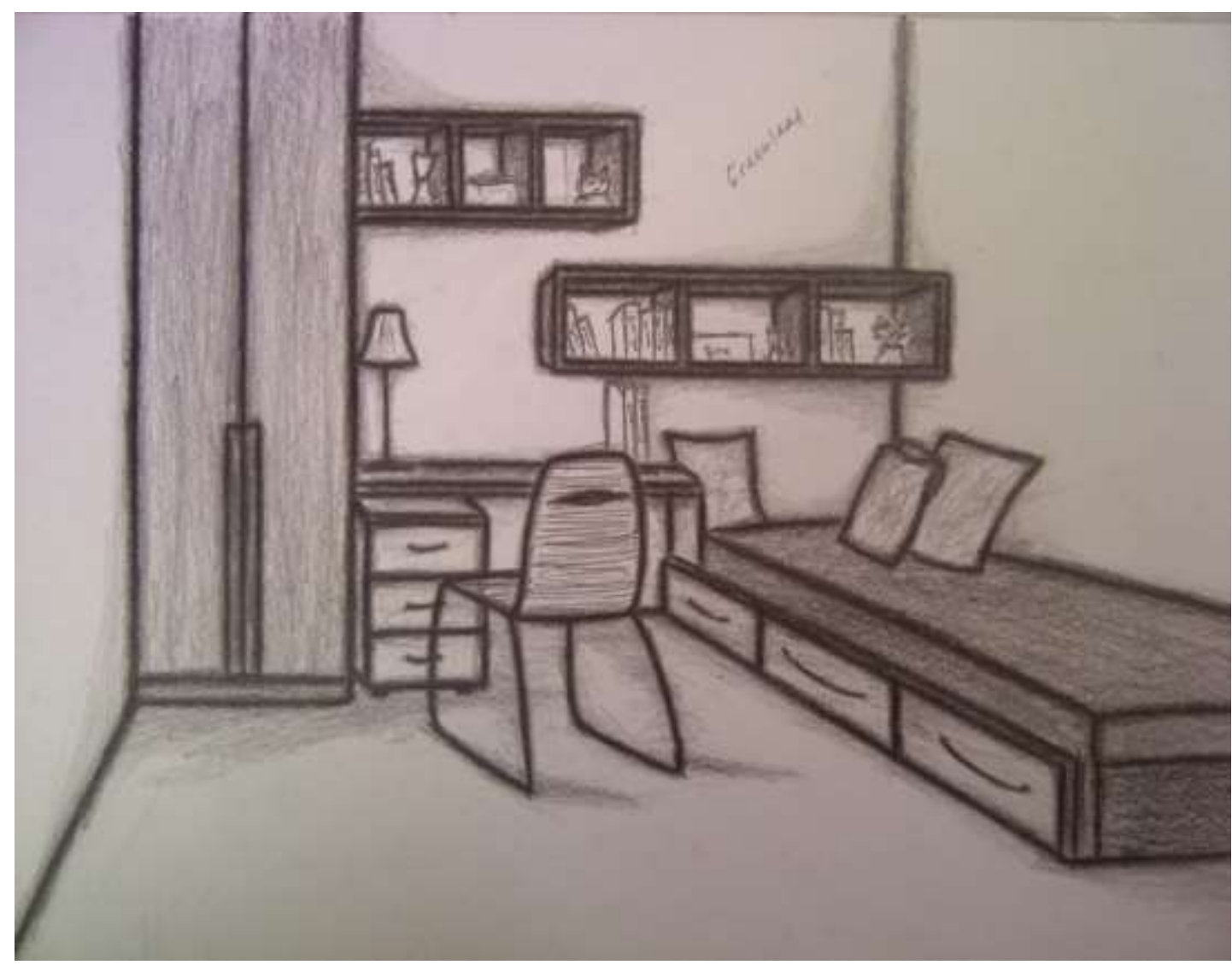

Gambar 1 : Sketsa Kamar Tidur Anak

Gambar 1 (satu) menunjukkan bahawa sketsa dari kamar anak ini menunjukkan bahwa ruang kamar tidur ini dengan interior yang menarik sehingga anak-anak lebih merasa nyaman dengan posisi tidur serta lebih pada sketsa kamar anak ini lebih terlihat elegan serta mendapatkan suasana keindahan pada kamar tidur anak dan pada pembuatan sketsa pada gambar satu ini dimana terdapat tempat tidur serta kursi, lampu tidur dan rak buku dimana 
pada sketsa ini penulis dapat mengkaji anatara gambar satu dan gambat dua dengan kenyamanan para anak-anak untuk betah terhadap rumah mereka masing-masing.

Pada pembuatan sketsa ini penulis sebelumnya melakukan tindakan survey terhadap kondisi kamar anak pada saat ini, dengan desain ruang tidur yang menarik para orang tua pun ingin membuat anaknya lebih betah untuk berdiam di rumah dibandingkan bermain di luar rumah, maka dari itu penulis membuat sebuah kajian dimana anak lebih betah dengan posisi interior kamar yang menarik.

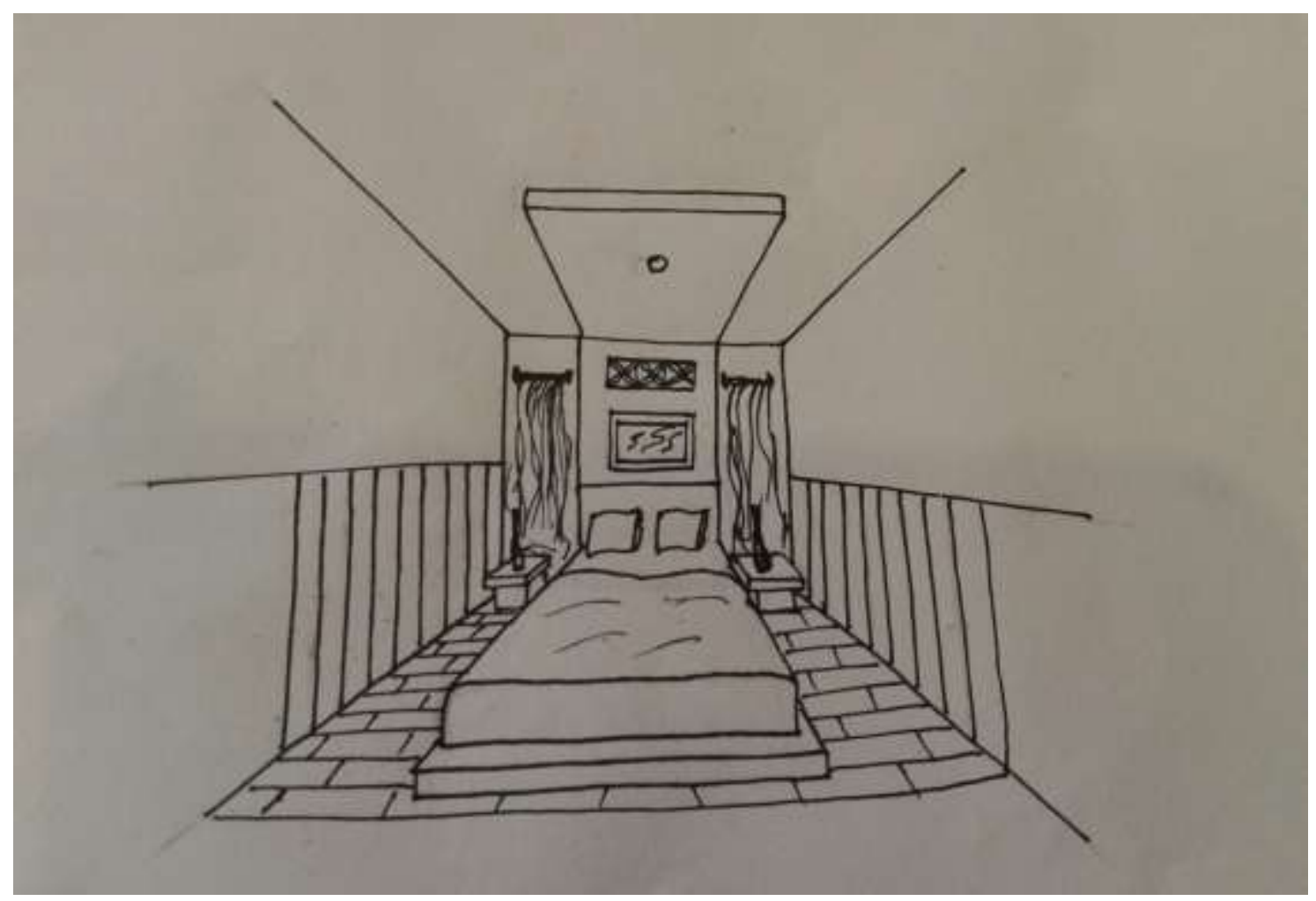

Gambar 2 : Sketsa Manual Kamar Tidur Anak

Pada gambar dua terdapat sketsa pilihan dari gambar pertama dimana pada gambar sketsa ini memiliki bentuk yang berbeda dari gambar pertama, sehingga dalam pembuatan ruangan tidur anak ini memiliki banyak sekali pilihan untuk mendapatkan hasil yang memuaskan, dengan desain yang kedua ini sangat simple dengan tata letak ruangan yang menarik dimana terdapat lemari serta hiasan dinding dan meja hias sehingga penulis pun membuat pilihan agar dengan sketsa yang minimalis ini peminat dapat memilih bentuk dan melihat model tata letak pada kamar tidur anak sehingga penelitian ini dapat dikaji oleh penulis.

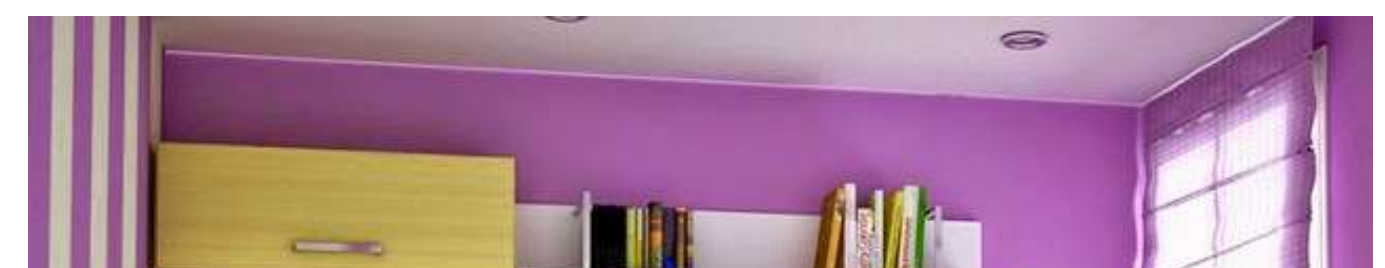




\section{Gambar 3 : Ruang Tidur Anak}

Kamar tidur adalah ruang yang bersifat amat pribadi yang mencerminkan karakter, keperibadian juga gaya hidup penghininya. Selain memenuhi tuntutan fungsi, tatanan kamar tidur yang baik tentu harus memperhatikan segi estetika atau aspek keindahan seperti pemilihan warna, corak serta gaya interior. Disamping itu, kamar tidur hendaknya mampu merefleksikan kepribadian pemiliknya agar kamar tersebut "berjiwa" dan benar-benar menjadi "surga" bagi penghuninya.

Kamar tidur anak yang ideal adalah kamar yang aman, sehat, serta dapat memacu kreatifitas dan mengembangkan imajinasi anak untuk pertumbuhan anak manjadi dewasa sehingga dalam kajian interior ruang tidur anak ini mendapatkan perhatian yang sangat lebih kepada masyarakat agar dalam mendesin kamar tidur anak lebih diutamakan untuk menonjolkan keindahan dikamar anak tersebut. Pada gambar tiga ini terdapat bentuk warna serta tata letak dari desain kamar anak tersebut dengan warna yang terdapat pada kamar anak ini membuat anak semakin betah engan banyaknya tampilan-tampilan unik pada gambar, serta pada gambar tiga ini dapat menjadi tujuan utama bagi penulis untuk mengkaji tempattidur anak yang lainnya.

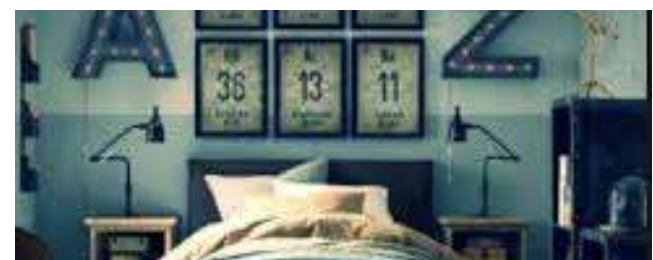




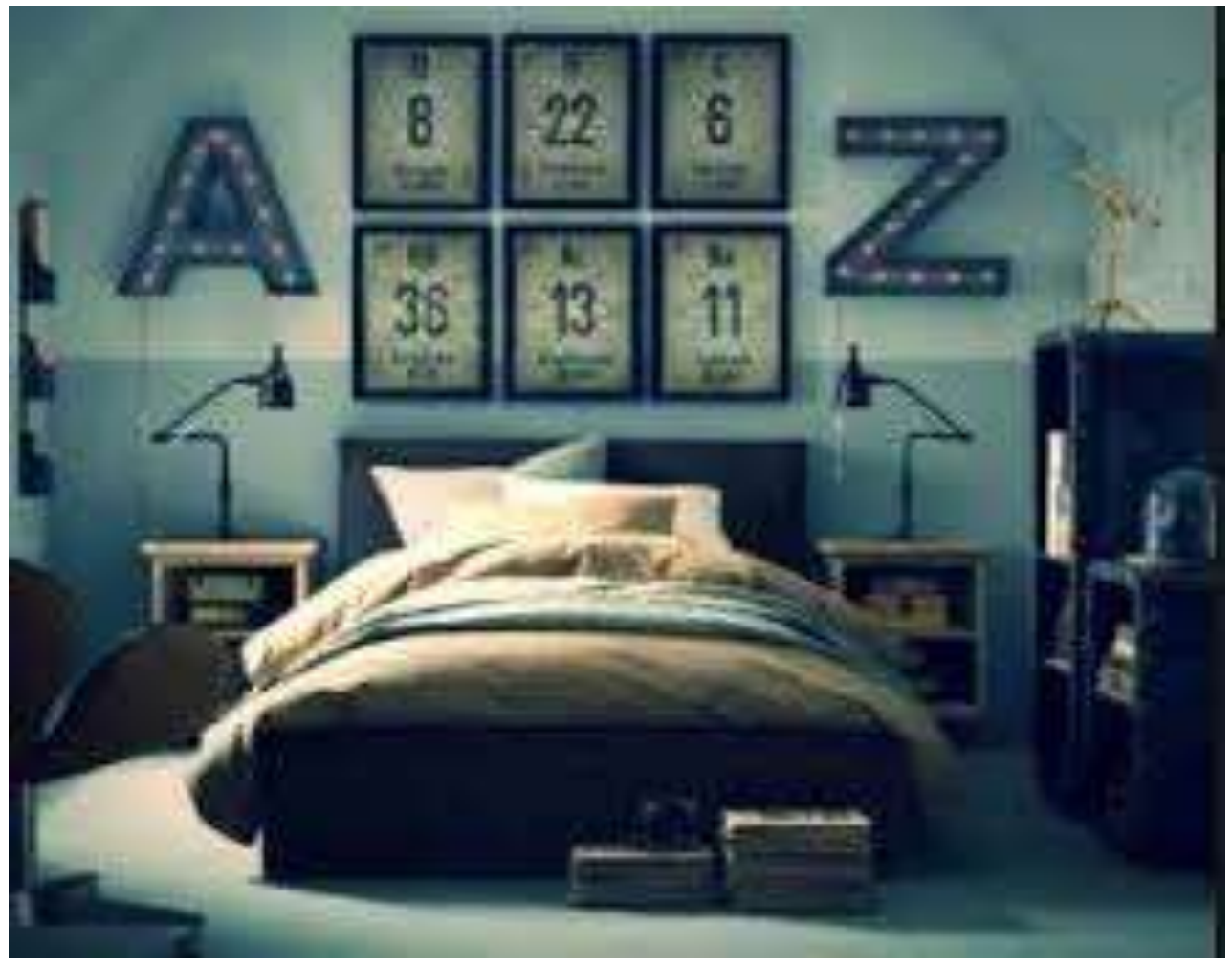

Gambar 4 : Ruang Tidur Anak Konsep Dua

\section{KESIMPULAN}

Berdasarkan hasil studi lapangan dan proses perancangan yang telah dilakukan, maka terdapat rumusan masalah yang menyatakan bahwa sebuah tempat tidur anak bersifat sederhana dan aplikatif yang dapat dirancang secara kelihatan lebih elegan sehingga memenuhi kebutuhan sesuai perkembangan usia dan aktivitas anak. Adapun tujuan dan manfaat yang diperoleh dalam perancangan ini ialah memberikan solusi desain terhadap masalah yang terjadi di lapanga berupa sebuah desain yang tidak disukai oleh para anak dan tempat tidur anak yang memiliki nilai fungsi yang lebih besar. Dengan adanya innovasi penetiti menkaji ruang tidur anak agar hal ini diharapkan dapat meningkatkan efisiensi dari seorang anak untuk betah dirumah serta kalangan orang tua pun lebih memperhatikan anaknya dikala anaknya berada di ruang hunian yang nyaman.

\section{DAFTAR PUSTAKA}

[1] Arsitektur Institut Teknologi Bandung. 2017. Prosiding Seminar Heritage IPLBI. Teknik sipil, Universitas Negri Semarang (UNNES) 2010. JURNAL TEKNIK SIPIL DAN PERENCANAAN VOL 12, No.1, 79-90

Online : 
[2] https://www.finansialku.com/desain-kamar-tidur-anak/

[3] https://dewakencana1404205068.wordpress.com/2016/09/15/pengertian-dasar-desaininterior/ 